\title{
AS CONTRIBUIÇÕES DO ESTÁGIO CURRICULAR EM GESTÃO E COORDENAÇÃO PEDAGÓGICA PARA A FORMAÇÃO DO PEDAGOGO NO MARAJÓ
}

\author{
Cleide Carvalho Matos \\ Manuelle Espíndola dos Reis \\ Universidade Federal do Pará (UFPA), Belém, Pará, Brasil
}

\begin{abstract}
Resumo: Este artigo tem como objetivo analisar as contribuições do Estágio curricular em gestão na escola e coordenação pedagógica para formação do pedagogo no Marajó. A pesquisa se caracteriza como pesquisa bibliográfica e documental. A pesquisa bibliográfica é constituída principalmente de livros, dissertações e artigos científicos. A pesquisa documental envolveu os seguintes documentos: Relatórios de estágio dos alunos do 70 semestre do curso da pedagogia, Projeto Pedagógico do Curso de Licenciatura em Pedagogia e a Lei $n^{\circ}$ 11.788/2008. O estudo aponta que o Estágio curricular em gestão na escola e coordenação pedagógica se configura como uma atividade formativa que possibilita a apreensão da realidade das escolas no Marajó e aproxima o aluno com um dos campos de atuação do pedagogo.
\end{abstract}

Palavras-chave: Formação de professores. Estágio curricular. Escola Campo. Coordenação pedagógica.

\section{INTRODUÇÃO}

O estágio sempre esteve presente nos cursos de formação de professores. Essa presença é marcada por dilemas e contradições, porém, é importante destacar que "o estágio é suporte essencial do desenvolvimento da competência técnica necessária ao futuro professor" (FAZENDA, 2002, p. 60). Pimenta (2012) ainda defende que o estágio nos cursos de formação de professores assuma um caráter investigativo da prática pedagógica.

Há algum tempo estamos envolvidas em trabalhos diretamente ligados a prática de ensino, a exemplo, a orientação de diferentes estágios dentre eles o Estágio curricular em gestão na escola e coordenação pedagógica que exige o acompanhamento dos alunos em campo no período da realização das atividades atinentes ao estágio. A leitura dos relatórios por eles produzido suscitou a seguinte indagação: Quais as contribuições do Estágio curricular em gestão na escola e coordenação pedagógica para formação do pedagogo no Marajó? Nesse sentido, o presente artigo busca analisar as contribuições do 
Estágio curricular em gestão na escola e coordenação pedagógica para formação do pedagogo no Marajó.

A pesquisa se caracteriza como uma pesquisa bibliográfica e documental. A pesquisa bibliográfica é constituída principalmente de livros, dissertações e artigos científicos. Para Tozoni-Reis (2009, p. 35), "a pesquisa bibliográfica tem como principal característica o fato de que o campo onde será feita a coleta de dados é a própria bibliografia sobre o tema ou objeto que se pretende investigar". Hissa (2013, p. 111) compreende a pesquisa bibliográfica "como um diálogo que se estabelece entre o sujeito da pesquisa e os diversos sujeitos, que também poderão ser postos em debates ao longo do texto, de modo a construir argumentos temáticos, teóricos e históricos acerca do que se pesquisa".

Também se recorreu a pesquisa documental, pois "a pesquisa documental tem como principal característica o fato de que a fonte dos dados, o campo onde se procederá a coleta de dados, é um documento (histórico, institucional, associativo, oficial, etc.). (TOZONI-REIS, 2009, p. 42). Nesse sentido, serão analisados os seguintes documentos: Relatórios de estágio dos alunos do $7{ }^{\circ}$ semestre do curso da pedagogia, o Projeto Pedagógico do Curso de Licenciatura em Pedagogia (PPC) e a Lei $\mathrm{n}^{\circ}$ $11.788 / 2008$, que dispõe sobre o estágio de estudantes.

O artigo está organizado em quatro seções, a saber: a introdução, que apresenta um breve histórico da formação do pedagogo e dos cursos de pedagogia no Brasil; a segunda seção, que trata do estágio curricular na formação do pedagogo, destacando a questão da prática de ensino como um dos dilemas que permeia a formação de professores desde suas origens, e discorre ainda sobre os instrumentos legais que normatizam o estágio curricular. A terceira seção apresenta os resultados e discussões sobre o Estágio curricular em gestão na escola e coordenação pedagógica no Marajó, discorrendo sobre o papel do estágio na formação docente, as atribuições e atividades desenvolvidas pelos coordenadores pedagógicos das escolas campo. E por fim, na conclusão, apresentamos as contribuições do estágio curricular em gestão e coordenação pedagógica para a formação do pedagogo no Marajó.

O artigo está organizado em quatro seções a saber: Introdução que apresenta um breve histórico da formação do pedagogo e dos cursos de pedagogia no Brasil; A segunda seção trata do estágio curricular na formação pedagogo destacando a questão da prática de ensino como um dos dilemas que permeia a formação de professores desde suas origens. Discorre ainda, sobre os instrumentos legais que normatizam o estágio curricular. A terceira seção apresenta os resultados e discussões sobre o Estágio curricular em gestão na escola e coordenação pedagógica no Marajó. Nessa seção discorre-se sobre o papel do estágio na formação docente, as atribuições e atividades desenvolvidas pelos coordenadores pedagógicos das escolas campo. E por fim, na conclusão apresentamos as contribuições do estágio curricular em gestão e coordenação pedagógica para a formação do pedagogo no Marajó.

\section{O ESTÁGIO CURRICULAR E A FORMAÇÃO DO PEDAGOGO}


A formação de professores vem sendo conclamada há bastante tempo. Segundo Saviani (2009), Comenius no século XVII foi o percussor desse debate, no entanto, somente em 1864 teria sido instituído o primeiro estabelecimento destinado a formação de professores, mas a questão só tem uma resposta institucional após a revolução francesa diante da necessidade de se pensar a instrução das classes populares, é desse contexto que decorrem as escolas normais. A primeira escola normal foi instalada em Paris em 1795, com duas formas de organização: a primeira, denominada escola normal superior, era voltada para a formação de professores que atuariam no ensino secundário, e a segunda forma de organização da escola normal era responsável pela formação de professores para atuarem no ensino primário. Esses modelos espalharam-se pela Europa e Estados unidos.

No Brasil a questão da formação de professores emerge de forma patente após a independência quando se cogita, de acordo com Saviani (2009), a instrução popular. Ainda segundo Saviani (2009), a preocupação com a formação de professores para a instrução popular se inicia com a aprovação da lei das escolas de primeiras letras em que os professores eram instruídos no método de ensino mútuo, modelo este que perdura até 1890, prevalecendo assim as escolas normais.

A primeira escola normal foi instalada no Brasil em Niterói, Rio de Janeiro em 1835, seguindo o modelo europeu, e as demais províncias trilharam o mesmo caminho. Para Saviani (2009), as escolas normais como responsáveis pela formação de professores para atuar nas escolas primárias, pregavam uma formação específica em seus currículos que deveriam ser guiados fundamentalmente por elementos didático- pedagógicos. No entanto,

O currículo dessas escolas era constituído pelas mesmas matérias ensinadas nas escolas de primeiras letras. Portanto, o que se pressupunha era que os professores deveriam ter o domínio daqueles conteúdos que Ihes caberia transmitir às crianças, desconsiderando-se o preparo didático-pedagógico. (SAVIANI, 2009, p.144).

A partir de 1932 teremos a presença dos institutos de educação, também responsáveis pela formação de professores, com objetivo de incorporar as demandas da pedagogia que buscava se afirmar como um conhecimento de caráter científico: "Caminhava-se, pois, decisivamente rumo à consolidação do modelo pedagógicodidático de formação docente que permitiria corrigir as insuficiências e distorções das velhas Escolas Normais". (SAVIANI, 2009, p. 146). No entanto, isso não ocorreu e a dissociabilidade entre teoria e prática continuou. A formação do bacharel ficou a cargo das Universidades e Faculdades de Filosofia, Ciências e Letras, e a prática, a cargo das escolas normais e dos Institutos de Educação. As escolas normais eram voltadas para a formação de professores das escolas primárias e os Institutos de Educação ofereciam a formação de grau médio, bem como cursos de especialização e aperfeiçoamento para os concluintes das escolas normais, conforme estabelecia a LDB n. 4.024/1961. Embora a existência dos Institutos de educação, as escolas normais, continuaram como responsáveis pela expedição do diploma de regente de ensino primário, e de professor primário.

Saviani (2009), destaca que na lei 5.692/71 a formação de professores poderia ocorrer de duas formas a saber: cursos curtos de licenciatura ( 3 anos) ou licenciatura plena (4 anos), cabendo aos cursos de pedagogia a formação dos especialistas sendo 
estes, diretores de escola, orientadores educacionais, supervisores escolares e inspetores de ensino.

A habilitação em gestão e coordenação pedagógica, segundo Silva (2006), ocorreu por meio do parecer 252/69, de autoria de Valnir Chagas. Foi a partir desse parecer que se estabeleceu um currículo mínimo para os cursos de pedagogia, a manutenção da formação para o exercício da docência e ainda a formação de especialistas para as atividades de orientação, administração, supervisão e inspeção de escolas e sistemas escolares, alterando a lei 5.540/1968 tornando obrigatória a formação desses profissionais.

Segundo Costa (2015), é nesse momento que é atribuído ao pedagogo a função de estudioso da teoria, dos fundamentos ou da metodologia da educação. Ainda nesse período, ocorre ampliação das funções do pedagogo, que poderá atuar como docente na educação especial, educação infantil e nas primeiras séries do ensino fundamental. A atuação na educação infantil e ensino fundamental era, de certa forma, uma extensão da formação recebida em nível médio/magistério. A LDB 9.394/1996 mantém a formação em nível médio/magistério como exigência mínima para atuar na educação infantil e anos iniciais do ensino fundamental.

De acordo com Pimenta (2002), o estágio curricular sempre esteve presente na formação de professores, assumindo diferentes nomenclaturas e espaços nos currículos dos cursos de formação. Segundo Pimenta (2002) nas escolas normais o estágio era disciplinado por uma legislação única, porém cada estado tinha a liberdade de disciplinar o estágio na formação docente o que contribuiu para diferentes entendimentos e formas de materializá-lo.

Pimenta (2002) esclarece que o estágio não é uma atividade formativa exclusiva dos cursos de formação de professores, pois para o exercício e formação de outros profissionais como os médicos há exigência do cumprimento tanto do estágio curricular como do profissional. Porém, na formação de professores, desde suas origens, temos a exigência do cumprimento do estágio curricular. Entende-se por estágio curricular "as atividades que os alunos deverão realizar durante o seu curso de formação, junto ao campo futuro de trabalho. Por isso costuma-se denominá-lo a 'parte mais prática do curso', em contraposição às demais disciplinas consideradas mais teóricas". (PIMENTA, 2002, p.21).

As discussões sobre os estágios supervisionadas têm se ampliado, assim como o entendimento sobre sua importância e articulação entre teoria e prática, "uma parte importante da relação trabalho-escola, e eles podem representar, em certa medida, o elo de articulação orgânica com a própria realidade". (FAZENDA, 1991, p. 64). Nesse sentido,

\footnotetext{
O estágio supervisionado deve ser considerado um instrumento fundamental no processo de formação do professor. Poderá auxiliar o aluno a compreender e enfrentar o mundo do trabalho e contribuir para a formação de consciência política e social, unindo teoria e prática. (FAZENDA,1991, p. 64).
}

A união teoria e prática também é uma das questões levantada por Pimenta (2001), no entanto, a autora enfatiza que várias pesquisas têm apontado o 
distanciamento entre ambas. Essa constatação vem acompanhando a formação dos professores desde suas origens conforme afirma Saviani (2009). Esse dilema na formação docente é fruto de modelos de formação que privilegiam os conteúdos em detrimento da prática ou vice-versa sendo "exatamente essa a situação da formação de professores diante do confronto entre os dois modelos: aquele centrado nos conteúdos culturaiscognitivos e aquele referido ao aspecto pedagógico-didático". (SAVIANI, 2009, p. 151).

Piconez (1991), ao analisar as leis 5.540/68 e 5.692/71 destaca a incompatibilidade entre elas, no que concerne a formação de professores, pois na primeira a ênfase está na formação de especialista enquanto a segunda volta-se para a formação de professores polivalentes.

Nas escolas normais a prática de ensino/estágio curricular se efetivava na disciplina de formação profissional: métodos e processos de ensino. Já nos cursos de licenciatura integrou minimante o currículo sob a forma de estágio supervisionado a partir da resolução 9 do Conselho Federal de Educação sob o parecer 672/69.

De acordo com Piconez (1991), o caráter complementar ou suplementar atribuído a prática de ensino/estágio supervisionado tem contribuído para o aprofundamento da dicotomia teoria e prática visto que a organização curricular dos cursos de licenciaturas coloca a teoria no começo do curso e a prática no final. A autora enfatiza ainda que não apenas a relação teoria e prática carecem de atenção, como também, a relação entre o estágio supervisionado e demais componentes curriculares, pois considera

$$
\begin{aligned}
& \text { a necessidade da estreita vinculação da didática, da prática de } \\
& \text { ensino com os demais componentes do curso de formação de } \\
& \text { professores em qualquer nível e/ou grau, para que se possa } \\
& \text { compreender o processo de ensino em suas dimensões histórico- } \\
& \text { social e política e ainda individual e coletiva". (PICONEZ, 1991, p. 23). }
\end{aligned}
$$

A prática de ensino possui uma dimensão dialética em que a teoria reflete na prática seus elementos e os confronta. Nessa relação faz-se a reflexão e por conseguinte a transformação da realidade:

[...] a dialética materialista demonstra como o sujeito concretamente histórico cria, a partir do próprio fundamento materialmente econômico, ideias correspondentes e todo conjunto de formas de consciência. Não reduz a consciência as condições dadas; concentra a atenção no processo ao longo do qual o sujeito concreto produz e reproduz a realidade social; e ele próprio, ao mesmo tempo, é nela produzido e reproduzido. (KOSÍK, 2011, p. 124).

Reflexão-ação-reflexão impõe a prática, uma perspectiva dialética, uma dimensão mais ampla, formativa, reflexiva e transformadora da realidade. Nesse sentido "a prática não fala por si mesma. Exige uma relação teórica com ela". (PIMENTA, 2002, p. 93).

A Lei de Diretrizes e Bases da Educação (LDB), 9.394/96 inspirada pelo processo de redemocratização do país, apresenta segundo Andrade e Rezende (2010) inovações importantes principalmente no que se refere a prática de ensino e da necessidade de 
interação entre teoria e prática. $\mathrm{O}$ artigo 61 Inciso II que trata dos profissionais da educação esclarece que:

\begin{abstract}
a formação dos profissionais da educação, de modo a atender às especificidades do exercício de suas atividades, bem como aos objetivos das diferentes etapas e modalidades da educação básica, terá como fundamentos: a associação entre teorias e práticas, mediante estágios supervisionados e capacitação em serviço. (BRASIL, 1996).
\end{abstract}

Andrade e Resende (2010), entendem que embora a legislação garanta a associação entre teoria e prática, mediante estágio supervisionado, essa relação só será possível se a estrutura curricular dos cursos de formação oportunizar essa associação. Caso essa articulação não aconteça, essa associação continuará a cargo dos alunos de licenciatura que terão de estabelece-la de forma autônoma assim como, não possibilitará a superação de modelos desarticulados e fragmentados em que teoria e prática caminham separadamente nos cursos de formação.

A LDB ainda determina no artigo 65 que a formação docente, exceto para a educação superior, incluirá prática de ensino de, no mínimo, 300 horas, estabelecendo claramente a prática de ensino como uma atividade formadora fundamental, sendo esta concepção reafirmada na lei 11.788/2008 em seu artigo $1^{\circ}$ que dispõe sobre o estágio de estudantes:

Estágio é ato educativo escolar supervisionado, desenvolvido no ambiente de trabalho, que visa à preparação para o trabalho produtivo de educandos que estejam frequentando o ensino regular em instituições de educação superior, de educação profissional, de ensino médio, da educação especial e dos anos finais do ensino fundamental, na modalidade profissional da educação de jovens e adultos. (BRASIL, 2008).

O reconhecimento do estágio como um ato educativo é de suma importância. No entanto, Libâneo (2012), chama a atenção para a necessidade de constituição de um paradigma de formação que considere a concepção de homem e de mundo em sua multidimensionalidade que possibilite ao profissional em formação o desenvolvimento de sua humanidade a partir da relação com conhecimentos produzidos historicamente e a realidade na qual está inserido.

Ainda no que se refere a prática de ensino na formação docente, em 2002 o CNE aprovou as Diretrizes Curriculares Nacionais para a Formação de Professores da Educação Básica, em nível superior, curso de licenciatura, de graduação plena. As diretrizes apresentam um breve histórico da política de formação de professores e dos marcos legais que a referendam em que a dissociação entre teoria e prática mais uma vez está presente no dilema sobre formação de professores. As diretrizes em sua concepção orientadora defendem que "a aquisição de competências requeridas do professor deverá ocorrer mediante uma ação teórico-prática, ou seja, toda sistematização teórica articulada com o fazer e todo fazer articulado com a reflexão". (BRASIL, 2001, p. 29), e: 
Todas as disciplinas que constituem o currículo de formação e não apenas as disciplinas pedagógicas têm sua dimensão prática. É essa dimensão prática que deve estar sendo permanentemente trabalhada tanto na perspectiva da sua aplicação no mundo social e natural quanto na perspectiva da sua didática. (BRASIL, 2001, p. 57).

O protagonismo atribuído pelas diretrizes a prática de ensino na formação de professores é preocupante, pois em nada ou pouco contribui para a superação dos modelos que vem permeando a formação docente, ao contrário, aprofunda a dicotomia presente nos cursos de formação e se distancia de um paradigma voltado para a formação humana, política, cidadã, técnica e pedagógica. Assim, "a formação deve ser de corpo inteiro, formação experienciada que dela decorram aprendizagens significativas, linguagens expressivas contra a alienação em atos e processos pedagógicos pouco ousados, nada criativos e sem indicativos de inovação". (LIBÂNEO, 2012, p. 80-81).

Refletir sobre a formação do professor e o papel das dimensões humana, política, cidadã, técnica e pedagógica é imprescindível para compreender a importância da formação no processo de emancipação do futuro profissional e por extensão de seu aluno. Na formação de professores, a dimensão pedagógica merece destaque conforme salienta Severino (2003) que

a docência em ambientes escolares institucionalizados não exaure o campo de atuação do profissional da educação, uma vez que educação não é sinônimo de ensino, pois significa também uma prática social de intervenção mais abrangente, alcançando outros espaços da vida da sociedade (SEVERINO, 2003, p. 73).

Por isso, o profissional em formação deverá participar das várias dimensões que envolvem a formação de professores, a saber: gestão, coordenação pedagógica, interação com os professores, participação em eventos realizados na escola e universidade, nas reuniões que envolvam escola, família e comunidade. Nesse sentido, o Estágio curricular em gestão na escola e coordenação pedagógica pode proporcionar o contato com um dos possíveis campos de atuação do pedagogo.

Na resolução $n^{\circ} 2$, de $1^{\circ}$ de julho de 2015, que define as diretrizes curriculares nacionais para a formação inicial em nível superior (cursos de licenciatura, cursos de formação pedagógica para graduados e cursos de segunda licenciatura) e para a formação continuada, a prática tem ênfase no processo de formação e acontece em diferentes momentos conforme destaque:

I- 400 (quatrocentas) horas de prática como componente curricular, distribuídas ao longo do processo formativo;

II - 400 (quatrocentas) horas dedicadas ao estágio supervisionado, na área de formação e atuação na educação básica, contemplando também outras áreas específicas, se for o caso, conforme o projeto de curso da instituição;

IV - 200 (duzentas) horas de atividades teórico-práticas de aprofundamento em áreas específicas de interesse dos estudantes, conforme núcleo definido no inciso III do artigo 12 desta Resolução, 
por meio da iniciação científica, da iniciação à docência, da extensão e da monitoria, entre outras, consoante o projeto de curso da instituição. (BRASIL, 2015, p.11).

O lugar de destaque da prática nas diretrizes e orientações para formação de professores ganha força a partir da década de 1980 e em nada contribui para a promoção de uma educação de qualidade.

\section{O ESTÁGIO CURRICULAR EM GESTÃO NA ESCOLA E COORDENAÇÃO PEDAGÓGICA E A FORMAÇÃO DO PEDAGOGO NO MARAJÓ}

O Município de Breves, um dos 16 municípios que compõe a Região de Integração do Marajó, é caracterizado, principalmente, pelo contraste de suas riquezas naturais e baixo índice de desenvolvimento humano. Tem uma população estimada em 99.896 habitantes, de acordo com o Instituto Brasileiro de Geografia e Estatística - IBGE (2019).

O Estágio curricular em gestão na escola e coordenação pedagógica compõe o currículo do curso de pedagogia da Universidade Federal do Pará - Campus Universitário do Marajó - Breves, desde de 2011, quando ocorreu a elaboração do Projeto Pedagógico do Curso de Licenciatura Plena em pedagogia. O Estágio curricular em gestão na escola e coordenação pedagógica tem como objetivo central promover atividades orientadas e supervisionadas sobre $\mathrm{o}$ trabalho de gestão escolar $\mathrm{e}$ coordenação pedagógica no contexto escolar junto a diretores e coordenadores pedagógicos da educação infantil, ensino fundamental e EJA.

Distribuído em 60 horas, o Estágio curricular em gestão na escola e coordenação pedagógica é dividido em dois momentos, a saber: orientação e campo. Além do mais, o Estágio tem como antecedentes as disciplinas: "Organização do trabalho pedagógico" e "Coordenação pedagógica em ambientes escolares". As orientações e discussões epistemológicas ocorreram em agosto de 2018. O período destinado a realização do estágio foi de agosto a novembro e a socialização ocorreu em dezembro por meio de um seminário que envolveu: alunos, professores da universidade e da educação básica, gestores, coordenadores pedagógicos, comunidade, e a secretaria municipal de educação.

Cabe destacar que cada professor, orientador do estágio, define o instrumento para o registro das atividades realizadas em campo: artigo, relatório, carta escolar, e relato de experiência, etc., assim como a forma de socialização, pois esse é um elemento obrigatório do estágio para que as experiências vivenciadas no mesmo sejam socializadas com os colegas, professor orientador e as instituições de ensino lócus do estágio.

O Estágio curricular em gestão na escola e coordenação pedagógica envolveu 27 alunos que cursavam o sétimo semestre do curso de pedagogia e foi realizado em cinco unidades de ensino. Neste estágio, os professores orientadores trabalharam com o instrumento de registro carta escolar, que apresentava dois eixos orientadores. São eles: conteúdos conceituais e conteúdo procedimentais. 
No eixo conteúdos conceituais, os estagiários deveriam investigar a escola como organização de trabalho e lugar de aprendizagem do professor, em termos da qualidade social do ensino, dos conceitos de organização, gestão, participação e cultura organizacional, dos princípios e características da gestão escolar participativa, do planejamento escolar e do projeto pedagógico-curricular, da organização geral do trabalho escolar, das atividades de direção e coordenação, das áreas de atuação do sistema de organização e gestão escolar, ações, procedimentos e técnicas de coordenação do trabalho escolar, formação continuada, avaliação de sistemas escolares e de escolas.

O eixo "conteúdos procedimentais", também de caráter investigativo, tem como objetivo compreender como ocorre no interior da escola a construção coletiva e realização interativa do projeto político-pedagógico da escola, as orientações para elaboração de plano de aula na perspectiva crítica, o acompanhamento da elaboração e implementação do projeto da coordenação pedagógica e gestão escolar, o acompanhamento da "apreciação/correção" do preenchimento de diário de classe, o monitoramento do boletim informativo (calendário escolar) da escola, o planejamento de reunião pedagógica e a participação ativa em sua realização e no planejamento de atividades para o trabalho com as famílias.

Nesse sentido, o Estágio curricular em gestão na escola e coordenação pedagógica é o espaço de formação em que o estagiário vai se aproximar de um dos campos de atuação do curso de pedagogia conforme o estabelecido no Artigo 64 da LDB 9.394/1996:

A formação de profissionais de educação para administração, planejamento, inspeção, supervisão e orientação educacional para a educação básica, será feita em cursos de graduação em pedagogia ou em nível de pós-graduação, a critério da instituição de ensino, garantida, nesta formação, a base comum nacional.

Em campo os alunos constataram que todos os coordenadores pedagógicos são licenciados em pedagogia, tem especialização em diferentes áreas e atuam tanto como coordenadores como professores na mesma ou outras escolas. O material produzido pelos estagiários apresenta várias situações que angustiam o coordenador pedagógico dentre elas destacamos: a estrutura física das escolas da rede municipal de ensino de Breves, a formação continuada dos profissionais docentes, a relação com a gestão e a relação com a comunidade. Foram muitas as questões que os alunos apresentaram em seu material de registro, no entanto, selecionamos essas por entendermos que são questões fundantes no trabalho do coordenador pedagógico.

Dentre as cinco unidades de ensino, campo do Estágio curricular em gestão na escola e coordenação pedagógica, apenas uma apresenta estrutura física satisfatória. Os coordenadores trabalham em pequenos espaços e/ou dividem espaço e equipamentos como o computador com o diretor da escola. As escolas apresentam problemas como: móveis danificados, salas não climatizadas, com ventiladores em péssimo estado de conservação, iluminação precária, falta de água, etc. Uma das escolas campo de estágio está em obra desde 2011, porém sem finalização os alunos e coordenadores ocupam o prédio escolar sem a estrutura adequada.

O material produzido pelos alunos no Estágio curricular em gestão na escola e coordenação pedagógica possibilitou compreender como as unidades de ensino estão 
em sua dimensão física, pedagógica e administrativa, o que permite uma reflexão sobre a realidade no percurso de sua formação, ampliando e ainda ressignificando o estágio como espaço de formação e de pesquisa:

A pesquisa no estágio é uma estratégia, um método, uma possibilidade de formação do estagiário como futuro professor. Ela pode ser também uma possibilidade de formação e desenvolvimento dos professores da escola na relação com os estagiários. (PIMENTA; LIMA, 2012. p. 143).

No que se refere a formação continuada dos educadores, uma das atribuições do coordenador pedagógico, "o trabalho do coordenador pedagógico é uma atividade voltada essencialmente à organização, à compreensão e transformação da práxis docente, para fins coletivamente organizados e eticamente justificáveis" (FRANCO, 2008, p. 120-121), e

O coordenador pedagógico é um profissional imprescindível para assegurar nas escolas a integração e articulação do trabalho pedagógico-didático: a formulação e acompanhamento da execução do projeto pedagógico-curricular, a organização curricular, a orientação metodológica, a assistência pedagógicodidática aos professores na sala de aula numa relação interativa e compartilhada com o professor e os alunos, colaboração nas práticas de reflexão e investigação, diagnóstico e atendimento de necessidades ligadas ao ensino e aprendizagem dos alunos em conjunto com o professor, atividades de formação continuada, práticas de avaliação da aprendizagem. (LIBÂNEO, 2012, p. 25).

Embora as atribuições do coordenador estejam intrinsicamente ligadas aos aspectos pedagógicos, o Estágio curricular em gestão na escola e coordenação pedagógica aponta que dentre as unidades de ensino campo do estágio apenas uma informou que trabalha a formação continuada do corpo docente. Segundo relatos a formação continuada é promovida por meio da Secretaria Municipal de Educação, através do Programa Nacional pela Alfabetização na Idade Certa (PNAIC).

Para Franco (2008), as dificuldades dos coordenadores em desenvolver as atividades inerentes à sua função estão relacionadas, principalmente, ao excesso de atividades que esse profissional realiza na escola, "de um modo geral as escolas são percebidas pelos coordenadores como espaços de pouco planejamento e muita improvisação, e as atividades cotidianas são conduzidas por ações espontaneístas, emergenciais, superficiais, baseadas no bom senso". (FRANCO, 2008, 123).

Os estudos de Franco (2008), apontam as angústias de coordenadores pedagógicos que embora tenham conhecimento das atividades que devem realizar admitem que gastam a maior parte de seu tempo com atividades burocráticas, preenchendo planilhas, fazendo relatórios, atendendo pais, etc.

A realização do Estágio curricular em gestão na escola e coordenação pedagógica apresenta as mesmas problemáticas. Em uma das escolas campo do estágio, no turno da noite, os professores faltam com frequência, "o que demandou que alguns 
professores ficassem sobrecarregados, em mais de uma turma ao mesmo tempo, levando o coordenador a sala de aula para desenvolver atividades para que os alunos não voltassem para casa" (CAVALCANTE et al, 2018).

Franco (2008), entende que a formação do coordenador pedagógico exige um papel de "faz tudo", pois desde a década de 1980 as discussões em torno da formação do pedagogo culminaram com uma formação inicial voltada para a docência não para a pesquisa da prática docência, retirando ou reduzindo o caráter essencial da pedagogia, outro fator está relacionado a falta de domínio de conteúdos de áreas específicas. Perceber as fragilidades e potencialidades da formação do pedagogo é fundamental para o processo de formação, permitindo que o estágio assuma outra dimensão:

Esse estágio pressupõe outra postura diante do conhecimento, que passe a considerá-lo não mais como verdade capaz de explicar toda e qualquer situação observada, o que tem conduzido estágios e estagiários a assumirem uma postura de irem às escolas e dizer o que os professores devem fazer. Supõe que se busque novo conhecimento na relação entre as explicações existentes e os dados novos que a realidade impõe e que são percebidas na postura investigativa. (PIMENTA; LIMA, 2012. p. 143).

Os registros produzidos nos estágios ainda apontam que uma das escolas campo não possui Projeto Político Pedagógico (PPP), documento norteador das ações da escola cuja formulação e acompanhamento da execução é atribuição do coordenador pedagógico.

Quanto a relação dos coordenadores pedagógicos com a gestão da escola os alunos identificaram que 0 diretor (gestor) fica responsável pelos aspectos administrativos como: solicitação de funcionário, garantia de alimentação escolar, frequência de servidor e providenciar os recursos humanos e materiais para o funcionamento da escola ficando a cargo do coordenador pedagógico as questões relacionadas aos aspectos pedagógicos.

Libâneo (2012), argumenta que o diretor precisa participar da dimensão didática-pedagógica da escola defendendo uma reestruturação do sistema, em que gerir uma escola ultrapassa as questões burocráticas e administrativas, pois a mesma deve ser compreendida como um espaço de aprendizagem, tanto quanto a sala de aula, em que,

\footnotetext{
[...] formas de funcionamento, normas, procedimentos administrativos, valores e outras tantas práticas que ocorrem no âmbito da organização escolar exercem efeitos diretos na sala de aula, sendo verdade, também, o inverso: o que ocorre na sala de aula tem efeitos na organização escolar". (LIBÂNEO, 2012, p. 15).
}

A relação dos coordenadores pedagógicos com a comunidade, segundo relatos na carta escola dos alunos estagiários, acontece por meio de reuniões sempre após o término de um bimestre por conta das avaliações. A cada bimestre pais e responsáveis são chamados na escola. Os coordenadores das escolas campo ainda informaram que a comunidade é chamada para participar da elaboração e revisão PPP da escola. 


\begin{abstract}
O coordenador pedagógico é um profissional imprescindível para assegurar nas escolas a integração e articulação do trabalho pedagógico-didático: a formulação e acompanhamento da execução do projeto pedagógico-curricular, a organização curricular, a orientação metodológica, a assistência pedagógicodidática aos professores na sala de aula numa relação interativa e compartilhada com o professor e os alunos, colaboração nas práticas de reflexão e investigação, diagnóstico e atendimento de necessidades ligadas ao ensino e aprendizagem dos alunos em conjunto com o professor, atividades de formação continuada, práticas de avaliação da aprendizagem. (LIBÂNEO, 2012, p. 25).
\end{abstract}

O coordenador pedagógico é o único profissional de suporte pedagógico presente nas instituições educacionais da rede municipal de ensino de Breves, pois, as escolas não contam com orientador nem supervisor escolar.

A presença do coordenador nas unidades de ensino de Breves é recente, precisamente a partir de 2003. A implantação da coordenação pedagógica nas escolas contribui para melhorar o trabalho pedagógico, todavia, o coordenador tornou-se o principal condutor dos processos pedagógicos das escolas, o que vem contribuindo para a sobrecarga de trabalho desse profissional.

A formação do pedagogo precisa considerar todos os aspectos de uma educação voltada para a formação humana, sensível na relação com a comunidade e promotora dos princípios democráticos nos espaços escolares.

\title{
CONCLUSÃO
}

O Estágio curricular em gestão na escola e coordenação pedagógica compõe o projeto Pedagógico do curso desde 2011 com objetivo de promover atividades orientadas e supervisionadas sobre 0 trabalho de gestão escolar e coordenação pedagógica no contexto escolar junto a diretores e coordenadores pedagógicos da educação infantil, ensino fundamental e EJA. A carga horária destinada à realização deste estágio é de $60 \mathrm{~h}$ voltadas para atividades teóricas e de campo.

Das cinco escolas campo apenas uma não possui PPP. Quando da elaboração do referido documento professores e comunidades são envolvidos no processo que é conduzido pelo coordenador pedagógico. As reuniões com pais, responsáveis e comunidade ocorre bimestralmente para tratar principalmente do resultado das avaliações dos alunos.

Dentre os principais entraves para a realização do trabalho dos coordenadores pedagógicos das escolas campo está o espaço físico das unidades de ensino que não possuem espaço específico para a realização de seu trabalho, tendo que dividir espaço e material com outros membros da escola.

No que se refere a organização do trabalho pedagógico das escolas, identificamos que coordenadores pedagógicos estão imersos em atividades que diferem de sua atribuição, por conta disso não realizam formação continuada com o 
corpo docente. A formação continuada fica sob responsabilidade da Secretaria Municipal de Educação que a promove por meio do Programa Nacional pela Alfabetização na Idade Certa (PNAIC).

Ainda foi possível identificar que a gestão pouco participa das atividades didática-pedagógica das escolas campo, limitando-se as atividades burocráticas. As atividades pedagógicas e muitas de cunho administrativo ficam sob responsabilidade do coordenador pedagógico.

O Estágio curricular em gestão na escola e coordenação pedagógica apresentase como um momento fundamental para a formação do pedagogo, pois permitiu que o contato com a realidade se constituísse, também, como um espaço de pesquisa da prática pedagógica.

Portanto, o Estágio curricular em gestão na escola e coordenação pedagógica possibilita a apreensão da realidade das escolas no Marajó aproximando os alunos do curso de pedagogia de um dos campos de atuação do pedagogo. As problemáticas e práticas positivas observadas nas escolas campo suscita novas indagações e possibilidade de transformação a partir de uma formação pautada em uma concepção dialética em que os elementos teóricos passam a subsidiar a prática e assim contribuir para a transformação da realidade.

Artigo recebido em: 31/01/2019 Aprovado para publicação em: 21/05/2019

\section{THE CONTRIBUTIONS OF THE CURRICULAR INTERNSHIP IN MANAGEMENT AND EDUCATIONAL COORDINATION FOR THE FORMATION OF THE EDUCATION TEACHER IN MARAJÓ}

ABSTRACT: This article aims at analyzing the contributions of the curricular internship in school management and educational coordination for the training of the education teacher in Marajó. The research is characterized as bibliographic and documentary research. Bibliographical research consists mainly of books, dissertations, and scientific articles. The documentary research involved the following documents: internship reports of the students of the 7th semester of the education degree, educational Project of college degree in education and Law $n^{\circ} 11.788$ / 2008. The study shows that the curricular internship in school management and educational coordination is a formative activity that allows the apprehension of the reality of the schools in Marajó and brings the student closer to one of the fields of action of the education teacher.

KEYWORDS: Teacher training. Curricular internship. School field. Educational coordination.

\section{LAS CONTRIBUCIONES DEL CURSO CURRICULAR EN GESTIÓN Y COORDINACIÓN PEDAGÓGICA PARA LA FORMACIÓN DEL PEDAGOGO EN EL MARAJÓ}

RESUMEN: Esto artículo tiene como objetivo analizar las contribuciones de la Etapa curricular en gestión en la escuela y coordinación pedagógica para la formación del pedagogo en el Marajó. La 
investigación se caracteriza como pesquisa bibliográfica y documental. La investigación bibliográfica es constituida principalmente de libros, disertaciones, artículos científicos. La pesquisa documental involucró los siguientes documentos: Informes de prácticas de los alumnos del $7^{\circ}$ semestre del curso de la pedagogía, Proyecto Pedagógico del Curso de Licenciatura en Pedagogía y Ley no 11.788 / 2008. El estudio apunta que la Etapa curricular en gestión en la escuela y coordinación pedagógica se configura como una actividad formativa que posibilita la aprehensión de la realidad de las escuelas en el Marajó y aproxima al alumno con uno de los campos de actuación del pedagogo.

PALABRAS CLAVE: Formación del profesor. Etapa curricular, Escuela campo. Coordinación pedagógica.

\section{REFERÊNCIAS}

ANDRADE, M. R.; RESENDE, R. de C. R. Aspectos legais do estágio na formação de professores: uma retrospectiva histórica. Educação em Perspectiva, Viçosa, v. 1, n. 2, p. 230-252, jul./dez. 2010. Disponível em:

https://periodicos.ufv.br/ojs/educacaoemperspectiva/article/view/6474. Acesso em: 03 jan. 2018.

BRASIL. Lei de Diretrizes e Bases da Educação. Brasília : Senado Federal, Coordenação de Edições Técnicas, 2017. Disponível em: http://www2.senado.leg.br. Acesso em: 12 jan. 2018.

BRASIL. Lei 11.788, de 25 de Setembro de 2008. Disponível em: http://www.planalto.gov.br. Acesso em: 12 jan. 2018.

BRASIL. Resolução CNE/CP No 2, DE 1० DE JULHO DE 2015. Define as Diretrizes Curriculares Nacionais para a formação inicial em nível superior (cursos de licenciatura, cursos de formação pedagógica para graduados e cursos de segunda licenciatura) e para a formação continuada. Disponível em: http://pronacampo.mec.gov.br/images/pdf/res_cne_cp_02_03072015.pdf. Acesso em: 10 maio 2018.

BRASIL. Lei n. 4.024/61. Estabelece as Diretrizes e Bases da educação nacional. Disponível em http://www.planalto.gov.br/ccivil_03/Leis/L4024.htm . Acesso em: 18 jan. 2019.

BRASIL. Lei no 9.394/1996. Estabelece as diretrizes e bases da educação nacional. Disponível em: Disponível em: http://www.planalto.gov.br/ccivil_03/Leis/L9394.htm. Acesso em: 12 jan. 2018. 
BRASIL. PARECER N. CNE/CP 009, de 8 de maio de 2001. Define as Diretrizes Curriculares Nacionais para a Formação de Professores da Educação Básica, em nível superior, curso de licenciatura, de graduação plena. Disponível em: http://portal.mec.gov.br/cne/arquivos/pdf/009.pdf. Acesso em: 10 de mai 2018.

CAVALCANTE, A. R. et al. Carta escolar: relatório final da disciplina Estágio Curricular em Gestão na Escola e Coordenação Pedagógica. Breves, 2018. Mimeo

COSTA, A. F. M. da. A prática Pedagógica no contexto da escola de tempo integral: desafios da educação integral e integrada. 2015. 113f. Dissertação. (Mestrado em Educação) Centro de Ciências da Educação, Universidade Federal do Piauí, Teresina, 2000. Disponível em:

http://ufpi.br/arquivos_download/arquivos/ppged/arquivos/files/Disserta\%C3\%A7\%C3 \%A30\%20VERS\%C3\%830\%20DE\%20ENTREGA\%20com\%20DATA.pdf Acesso: 05 de Jan. 2018.

FAZENDA, Ivani Catarina Arantes. O papel do estágio nos Cursos de Formação de professores. In: PICONEZ. S. C. B. A prática de ensino e o estágio supervisionado. Campinas, SP: Papirus, 1991. (Coleção Magistério: Formação e trabalho pedagógico).

FRANCO, M. A. S. Coordenação pedagógica: uma práxis em busca de sua identidade. Revista Múltiplas Leituras, São Paulo, v.1, n. 1, p. 117-131, jan. / jun. 2008. Disponível em: https://www.metodista.br/revistas/revistasims/index.php/ML/article/viewFile/1176/1187 . Acesso em: 20 nov. 2018.

HISSA, C. E. V. Entre notas: Compreensão da pesquisa. Belo Horizonte. Editora: UFMG, 2013.

KOSIK, K. Dialética do concreto. Tradução de Cecília Novaes e Alderisco. $2^{\mathrm{a}}$ ed. Rio de Janeiro: Paz e Terra, 2011.

LIBÂNEO, J. C. Identidade da pedagogia e Identidade do pedagogo. In: BRABO, T. S. A. M.; CORDEIRO, A. P.; MILANEZ, S. G. C. (org.). Formação da pedagoga e do pedagogo: pressupostos e perspectivas. Marília: Oficina Universitária; São Paulo: Cultura Acadêmica, 2012.

LIBÂNEO, J. C. Organização e gestão da escola: teoria e prática. 5. ed. Revista e ampliada. Goiânia: MF livros, 2008.

PICONEZ, S. C. B. A prática de ensino e o estágio supervisionado: a aproximação da realidade escolar e prática de reflexão. In: PICONEZ. S. C. B. A prática de ensino e o estágio supervisionado. Campinas, SP: Papirus, 1991. (Coleção Magistério: Formação e trabalho pedagógico). 
PIMENTA, S. G. O estágio na formação de professores: unidade teoria e prática? $5^{\circ}$ ed. São Paulo: Cortez, 2002.

PIMENTA, S. G.; LIMA, M. S. L. Estágio e Docência - Teoria e Prática: diferentes concepções. In: BRABO, T. S. A. M.; CORDEIRO, A. P.; MILANEZ, S. G. C. (org.). Formação da pedagoga e do pedagogo: pressupostos e perspectivas. Marília: Oficina Universitária; São Paulo: Cultura Acadêmica, 2012.

SAVIANI, D. Formação de professores: aspectos históricos e teóricos do problema no contexto brasileiro. Revista Brasileira de Educação, Rio de Janeiro, v. 14, n. 40 jan./abr. 2009.Disponível em: www.sielo.br/pdf/rbedu/v14n40/v14n40a12.pdf. Disponível em: 11 dez. 2018.

SEVERINO, A. J. Preparação técnica e formação ético-política dos professores. In: BARBOSA, R. L. L (Org.). Formação de educadores: desafios e perspectivas. São Paulo: editora UNESP, 2003.

TOZONI-REIS, M. F. de C. Metodologia da pesquisa. 2.ed. Curitiba, PR: IESDE, Brasil, S.A., 2009.

Cleide Carvalho Matos: Doutora em educação pelo Programa de Pós-graduação em Educação da Universidade Federal do Pará, PPGED/UFPA (2016), Mestre em Educação, PPGED/UFPA (2010), Especialista em Estudos Culturais da Amazônia pela UFPA (2004) e Graduação em Pedagogia pela UFPA (2002). É Professora Adjunto 2 da Universidade Federal do Pará, Campus Universitário do Marajó, Breves, exercendo a docência no curso de Pedagogia. Tem experiência nos seguintes temas: formação de professores, didática, currículo e educação do campo. Pesquisadora no Núcleo de Estudos e Pesquisas em Currículo, NEPEC. Vice-Líder do Grupo de Pesquisa GEPECAMPO. É integrante da Associação Nacional de Pós-graduação e Pesquisa em Educação e da Associação Nacional de Política e Administração da Educação.

Orcid: https://orcid.org/0000-0003-3740-0692

E-mail: cleidematos@ufpa.br

Manuelle Espíndola dos Reis: Mestra em Gestão Pública pela Universidade Federal do Pará (UFPANNAEA) (2016), Licenciada Plena em Pedagogia e letras pela Universidade Federal do Pará (2008). Atualmente é Professora Técnica Pedagógica Educacional na Secretaria Municipal de Educação (2015 até o presente) e professora da educação infantil no município de Breves-PA desde 2017 até a presente data.

Orcid: http://orcid.org/0000-0001-5211-3689

E-mail: manuelleespindola@hotmail.com

Este periódico utiliza a licença Creative Commons Attribution 3.0, para periódicos de acesso aberto (Open Archives Iniciative - OAI). 